\title{
EL TOPÓNIMO CONDEVILLA: CUESTIONES DE IDENTIDAD E INTERDISCIPLINARIEDAD
}

\author{
María del Carmen Llontop Castillo y Gloria Pozo Neira \\ Universidad Ricardo Palma
}

\begin{abstract}
RESUMEN
El interés por realizar trabajos de investigación lingüística en el área de la onomástica ha proliferado en los últimos años y con mucha innovación metodológica, especialmente los trabajos toponímicos los hay en gran número. Se tienen los estudios toponímicos de Canta, de la cuenca del río Chicama, así como de Cajamarca, del topónimo de Ancash, de la Provincia de Juli y de otros lugares representativos para el país. Condevilla es el topónimo de una urbanización del distrito de San Martín de Porres y se presenta con el objetivo de revalorizar la historia local, con la finalidad de ayudar a construir una identidad más sólida de los lugareños, dentro de un país donde la desigualdad puede apoyarse, incluso, en el gentilicio que se le otorga a una persona.
\end{abstract}

\section{PALABRAS CLAVE}

Topónimo / Información histórica / Mapas topográficos / Étimo original / Filológico.

\begin{abstract}
The interest in conducting linguistic research in the area of onomastics has proliferated in recent years, with many methodological innovations, notably toponymic work there are in large numbers. They have Canta toponymic studies of Chicama River Basin and of Cajamarca, Ancash of the name, of the Province of Juli and representative points for the country. Toponimo Condevilla is a residential district of San Martin de Porres and is presented with the aim to revalue local history, in order to help build a stronger identity of the locals, in a country where inequality can be supported even in the adjective that is given to a person.
\end{abstract}

\section{KEY WORDS}

Place name / Historical information / Topographical / Maps / Etymon original / Philological. 


\section{INTRODUCCIÓN}

El topónimo Condevilla designa a una urbanización del distrito de San Martín de Porres y forma parte de uno de uno de los cinco valles existentes en Lima, según el documento colonial Relación de las 223 haciendas de los cinco valles de Lima con nómina de propietarios, producción e impuestos (Lima, 28 de febrero de 1780) (Colección documental de la Independencia del Perú, 1976); además los mapas 22 y 29 de la gran colección de mapas topográficos de Gunther recopilados desde 1613 hasta 1983, dan cuenta de un pequeño espacio geográfico denominado actualmente Condevilla que se encuentra ubicado dentro de los alrededores de Lima Metropolitana.

Los trabajos de toponimia tienen su importancia porque contribuyen a la Lingüística, a la Historia, a la Arqueología y a la Educación. Conocer el origen etimológico de un nombre, los cambios que se han producido en él, las lenguas que influyeron en su formación y en consecuencia los patrones culturales que traen consigo, pueden contribuir a la formación de la identidad de un determinado pueblo, asentamiento humano, urbanización o distrito. Se puede descubrir, incluso, lugares con cierta riqueza mineral aludiendo al significado del nombre, o dar cuenta que en un determinado lugar confluyeron varias culturas, situación que ha ocurrido con el topónimo Condevilla. En esta investigación se presenta la indagación etimológica del topónimo en mención, a través de un trabajo interdisciplinario, ya que no solo se ha buscado información lingüística, sino también información histórica y arqueológica para describir de manera idónea este étimo. La contribución de los diccionarios en lenguas nativas andinas y datos catastrales obtenidos en la Municipalidad de Lima fueron útiles para este propósito.

\section{PROCEDIMIENTO DE LA INVESTIGACIÓN}

Para iniciar la investigación se formuló el problema toponímico, se revisaron diferentes antecedentes sobre estos estudios y se realizó la descripción de la zona involucrada. Así también se tomaron como referencia algunos mapas otorgados por el Instituto Geográfico Nacional y los planos de Gunther, que suman un total de 31 mapas. De estos documentos se obtuvo un corpus del topónimo, que permitió iniciar el análisis lingüístico para identificar el étimo original y sus diferentes variaciones a través del tiempo, así como presentar la sintaxis del mismo. 


\section{ANTECEDENTES}

Todo el territorio nacional presenta nombres geográficos que pueden ser vinculados al español, mientras que otros por su ininteligibilidad pueden ser aludidos a una lengua nativa. Cerrón Palomino, Gustavo Solís y otros investigadores en su "Guía para los estudios de toponimia" dan cuenta de esta realidad, e incluso plantean que ciertos topónimos pueden tener significados enigmáticos y no necesariamente describir la realidad física del lugar como muchos topónimos lo hacen. De tal forma, un topónimo puede aludir a creencias e idiosincrasias. Según informa la guía, los estudios toponímicos en nuestro medio empiezan a cambiar a partir de 1976, porque se producen los primeros intentos de aprovechar los aportes de la Lingüística, los resultados de los estudios de las lenguas andinas y sobre todo, del trabajo interdisciplinario con el fin de proveer estudios serios y fructíferos de los nombres geográficos. El primer estudio de este tipo, que propone una metodología para clasificar los étimos y aprovecha los resultados de la arqueología es la investigación de los polacos Krzonowsky, A. y Szeminski (1974) La toponimia indígena en la cuenca del río Chicama. Otro aporte a los trabajos de toponimia constituye la investigación de Gustavo Solís El topónimo Áncash y las limitaciones de la ciencia de la Toponimiay el artículo "Sistemas de denominación toponímica Quechua y Aru..." donde menciona dos postulados sobre las denominaciones de los lugares: "Los lugares tienen cosas...los lugares hacen cosas...". De igual modo la investigación realizada por Ana Baldoceda Toponimia de Canta, proporciona una metodología apropiada.

\section{DESCRIPCIÓN DE LA ZONA}

El topónimo designa a una urbanización del distrito de San Martín de Porres del Departamento de Lima. Se encuentra ubicada -según la relación de haciendas mencionada en la introducción- en lo que era uno de los cinco valles de Lima, el valle de "Caravaillo" en el camino desde "El Coronel" hasta "El Romeral" cerca de las chacras de Bocanegra, Oquendo y Naranjal.

\section{OBJETIVOS DE INVESTIGACIÓN}

a. Explicar la formación del topónimo Condevilla y la sucesividad de su denominación.

b. Reconstruir la historia desconocida de la urbanización. 


\section{RAZONES DE IDENTIDAD}

\section{a. RAZONES HISTÓRICAS}

El topónimo Condevilla, según fuentes históricas revisadas, alude a un lugar prehispánico de la cultura Lima radicada en los valles de Ancón, Chillón, Rímac y Lurín; es decir en la Comarca de Lima y llega hasta Huancoy, Ñaña y Huaycán, ascendiendo por el cauce de los tres últimos ríos que existían por la zona. Es posible que el área de difusión haya llegado hasta Canta en la cuenca del Chillón y San Pedro de Casta y Matucana en la del Rímac. Se postula que los Lima eran de origen aymará. El padre Villar Córdova, uno de los más importantes estudiosos de la arqueología del departamento de Lima, demuestra filológicamente el origen aymará de la mayor parte de las viejas poblaciones de la comarca limeña. El análisis etimológico de los nombres y el estudio de los ceramios, que realizan los historiadores sobre el área limeña, se constatan como evidencia de la influencia de los Tiawanaku-wari. En la Comarca de Lima, al finalizar el apogeo Wari, al parecer se produjo una invasión de los pueblos aymarás y contribuyó a la desarticulación del dominio imperial de la región, poco después a su desaparición. Posiblemente en esa época, llegaron a la Costa Central algunos grupos y aprovechándose el debilitamiento de los wari se establecieron en ella. El padre Villar afirma que fueron tres las etnias que llegaron hasta la Comarca de Lima:

1. Los Collas, que desde las serranías canteñas bajaron por la quebrada de Arahuay y se esparcieron por la banda izquierda del río Chillón, ocupándola desde Yangas hasta el Callao.

2. Los Huallas, que descendieron desde el Alto Chancay hasta la costa, fundando poblaciones tales como Kara Huallas, Maranca, HuadcaHualla, Sulco y Marca Huillca.

3. Los Huanchos, quienes iniciaron su expansión hacia la costa desde las alturas de Huarochirí y a través de los cauces de los ríos Santa Eulalia y Rímac, llegaron hasta la parte media de este último valle, estableciéndose en Huachipa, Huacho Huallas, Carapongo, Huampaní, Caxamarquilla, Pariachi, Lati y HurinHuancho.

Según María Rostworowski de Diez Canseco -en Agurto, S. (1974)- quien es una historiadora especializada en asuntos relativos a la sociedad costeña prehispánica, plantea la siguiente organización política:

... al norte existía el Señorío de Chuquimanco, que comprendía los valles de Mala, Omas, Chilca y Cañete, el antiguo Huarco; al noreste el Señorío de los Atavillos, que se extendía desde las sierras de Cajatambo 
hasta los de Canta, inclusive; al sureste el Señorío de los siete Guarangos de Huarochirí, que ocupaba las serranías de Cañete hasta Canta; y en la Comarca de Lima gobernaban los Señoríos de Ichma y Colli, abarcando, el primero, el valle de Lurín y la parte baja de Lima; y el segundo, la cuenca del río Chillón, desde Quivi hasta el mar (Agurto, 1974).

De acuerdo a las consideraciones de María Rostworowski, la parte baja del valle del Rímac, pertenecía al Señorío de Ichma, y estaba organizada en varios pequeños curacazgos cuyos territorios se ubicaban de acuerdo al sistema de canalizaciones existentes. Los curacazgos fueron los de: Sulco, Guatca, Lima, Maranca y Callao. El curacazgo de Lima en especial, se extendía en torno del cauce de la acequia llamada posteriormente de la Magdalena, la que se originaba en una toma ubicada detrás del actual Palacio de Gobierno. Los límites del cacicazgo llegaban por el suroeste hasta el mar y es posible que por el noroeste abarcaran los distritos de Lurigancho y el Rímac, San Martín de Porres, Lima, Breña, Pueblo Libre, Magdalena del Mar y San Miguel. Su sede de gobierno fue el pueblo de Lima ubicado en lo que hoy es la Plaza de Armas y alrededores. Todos estos antecedentes históricos hacen hipotetizar que el topónimo Condevilla tenga influencia aymará y también quechua; aunque la población piensa que el nombre correspondía a la del Conde de Villa, que según los lugareños fue el dueño inicial de la Urbanización. Si se esclarece el origen del nombre Condevilla, se contribuye definitivamente a la historia del distrito de San Martín de Porres.

\section{b. RAZONES LINGÜÍSTICAS}

Los topónimos son emisiones lingüísticas motivadas por la entidad geográfica, por la cultura o del sentido que tenga para que un lugar sea una identidad que posee una individualidad que la diferencia de otros lugares y del hecho que sea útil y que por lo tanto valga la pena nombrarlo; por otro lado, se tiene en cuenta el principio genérico - específico para nombrar lugares, el cual es altamente eficiente y bastante expandido como para considerarlo universal y además yace el principio básico de la clasificación de las formas, del debilitamiento y modificaciones ortográficas que contribuyen a disminuir la transparencia del sistema original del topónimo y por lo tanto su transformación a través del tiempo.

\section{CRITERIOS METODOLÓGICOS}

Para recoger la información de esta investigación se utilizó el método descriptivo- exploratorio, el método histórico-filológico, bibliografía específica, un corpus extraído de los mapas consultados y entrevistas a lugareños. 
Se revisaron 31 mapas topográficos, así como se transcribieron grabaciones y se elaboraron fichas de trabajo toponímico para obtener los resultados esperados. La técnica de aplicación se basó en la revisión de los étimos o entradas recogidas de los diferentes mapas, con los cuales se formó un corpus, a través de la secuencia que a continuación se presenta:

- Se extrajeron los nombres de los lugares de cada uno de los mapas.

- Se ordenaron alfabéticamente los nombres que aludieron al lugar investigado.

- Se procedió a la comparación de los diferentes nombres, verificando la variación o cambios que se están produciendo.

- Se analizaron a definir la sintaxis del étimo original.

- Se analizaron los mapas que dieron cuenta de la variación del topónimo Condevilla.

En el análisis se realizó un trabajo descriptivo - exploratorio y los resultados fueron obtenidos como producto de una comparación de fichas así como de la verificación de la información de las fuentes topográficas.

La población y muestra de la investigación estuvieron constituidas por el corpus extraído de los mapas topográficos y de las fuentes históricas.

La hipótesis de trabajo fue "El topónimo Condevilla se relaciona con la lengua castellana pero su sintaxis tiene influencia andina”.

\section{LIMITACIONES}

Todo trabajo de toponimia tiene limitaciones, en la investigación del topónimo Condevilla se encontraron las siguientes:

- El distrito San Martín de Porres, que alberga a la urbanización Condevilla, es de creación reciente y no sustenta documentos antiguos que den cuenta de la denominación original o más antigua de la urbanización motivo de la investigación.

- No se puede contar con buenos informantes de la zona ya que las personas de mayor edad no cuentan con una información adecuada y los fundadores de la urbanización ya murieron.

- La dificultad mayor se encuentra en la accesibilidad de documentos antiguos en diferentes instituciones que presentan fuentes bibliográficas, ya que no permite el acceso libre a las fuentes, sino a través de cartas de presentación y sólo en días específicos.

- El tiempo que se tiene dispuesto para investigar siempre es limitado. 


\section{ANÁLISIS DEL CORPUS OBTENIDO DEL ANÁLISIS DESCRIP- TIVO FILOLÓGICO}

El topónimo Condevilla ha sufrido una serie de modificaciones a través del tiempo. La fecha en que se inicia su modificación y en la cual se puede ya dar cuenta de su presencia en documentos topográficos es en 1780.

El 28 de febrero de 1780 en la Relación de las 223 haciendas de los cinco valles de Lima con nómina de propietarios, producción e impuestos que fue enviada a España para dar cuenta de los tributos que se recibían en el Perú, aparecen dos haciendas ubicada en la zona investigada con los nombre: Chacra Villa Señor la Baja, cuyo propietario fue Don Pablo Alvarado, y la Chacra Villa Señor Alta, cuyo propietario fue Don Francisco Laynes. En el plano topográfico de Lima, Callao y alrededores trazado y dibujado por Camilo Vallejos, publicado en 1907 por Alejandro Garland, incluye por primera vez el Valle de Chillón y alrededores en una escala del 1/80 000. Este plano ha consultado previamente el plano topográfico del ingeniero del Estado Dr. Luis Mariani de 1857 y presenta los siguientes nombres para los mismos lugares: Conde Villa Señor Alto, y Conde Villa Señor Bajo.

En los inicios del siglo XX los pobladores de la zona pensaban que los dueños de las chacras ostentaban el título de Conde.

Ya en 1780, a los lugares que eran considerados capitales de distrito deberían ser nombrados "villas", por lo que se deduce que originariamente el lugar se denominó: Chacra Señor Alto y Chacra Señor Bajo. Después se agregó, entonces, la palabra "villa".

El análisis de los nombres presentes desde el mapa 22 hasta el 29 pertenecientes a la gran colección de los Planos de Lima de Juan Gunther (1613-1983) y la constatación de estos con otros documentos coloniales hacen concluir:

1. El étimo original del topónimo Condevilla es de origen castellano y realmente fueron dos:

- Chacra Señor Alta

- Chacra Señor Baja

Los términos alta y baja se deben a la influencia andina en la zona, si nos remitimos a las consideraciones históricas mencionadas en párrafos anteriores, la zona tuvo contacto aymará y quechua (señoríos 
de procedencia andina tuvieron como propiedad esos territorios) y la palabra chacra alude a la fundación agraria que el lugar tenía.

2. Estos nombres sufren una primera modificación en su sintaxis, al agregarse por decisión política el término "villa":

- Chacra Villa Señor Alta

- Chacra Villa Señor Baja

3. Después que las haciendas fueron expropiadas y dejaron de ser zonas agrarias fueron vendidas a corporaciones de construcción y vivienda, por lo cual la zona fue urbanizada y pasó a tener diferentes propietarios en forma privada. Los pobladores de esta zona, posteriormente, agregaron al nombre la palabra Conde (Según se registra en los planos de 1857) porque asumían que el anterior propietario tenía dicho título (información recopilada a través de entrevistas), aunque si revisamos la Relación de haciendas... de 1780, los propietarios originales fueron Don Pedro Alvarado (para la parte baja) y Don Francisco Laynes (para la parte baja). Pero es natural que muchos lugares en Lima lleven nombres cuyo origen solo puede explicarse a través de una denominación popular o folclórica; es decir, a través del tiempo los lugareños pueden agregar, a la sintaxis del étimo original, otras palabras; cambiando por completo su estructura. Por este motivo, es que luego se tiene la construcción: Conde de la Villa Señor Alto, que alterna con Conde Villa Señor Bajo. Esta variación se observa en el mapa 22 de Gunther.

4. Por cuestión de economía lingüística los pobladores han reducido la sintaxis del topónimo a Condevilla Señor Altoy Condevilla Señor Bajo. La vocal del término final cambia cuando se le agrega la palabra Conde.

5. En la actualidad el topónimo se ha reducido, también por economía, a Condevilla para la parte alta y Condevilla Señor para la parte baja.

6. Los jóvenes del lugar no hacen esa diferenciación, ambas zonas son llamadas Condevilla. Solamente las personas adultas a partir de los 50 años, aproximadamente, hacen la diferencia; porque para ellos la zona que se encuentra al lado derecho de la gran avenida José Granda es Condevilla y la zona que se encuentra al lado izquierdo, de esa misma avenida, es Condevilla Señor. 


\section{CONCLUSIONES}

Esta investigación es interdisciplinaria, porque ha tomado los recursos de la Lingüística, de la Historia, de la Arqueología, como del conocimiento popular. Se parte teóricamente de que los topónimos tiene un étimo original y que este proviene de una lengua - cultura, pero que los cambios diacrónicos y la sucesividad de las etapas culturales hacen oscurecer el étimo. Si bien el topónimo Condevilla es producto de una composición lexemática del español, no debe dejarse de lado la influencia andina que los documentos históricos dan cuenta, por lo que actualmente existe una dualidad en la denominación de la zona, tal vez una herencia de los habitantes de la época prehispánica de Lima, cuya cosmovisión mantenía la dualidad alto - bajo en la concepción de su espacio geográfico. La investigación lingüística en el área de la toponimia no puede presentarse de manera acabada sin la contribución de otras disciplinas y de un trabajo analítico de carácter filológico por lo que se hace necesario el apoyo de diferentes especialistas y de un trabajo muy riguroso en cuanto a metodologías.

Las investigaciones toponímicas, como esta, contribuyen definitivamente a formar la identidad de una población, a construir un espíritu de respeto y de orgullo al legado cultural. La población cuando conoce su origen se siente más identificada con lo que tiene y trata de preservarlo, evita toda comparación negativa y por lo tanto todo trato desigualitario. Muchos distritos de Lima tienen nombres que han sufrido modificaciones a través del tiempo, pero pocos de ellos tienen un origen que la Historia y la Arqueología pueden explicar, como es el caso del nombre Condevilla; para otros lugares, los documentos solo registran nombres modernos implantados por el buen sonido o por el gusto (actitud lingüística) que el poblador tenga frente a ese nombre y decida colocárselo al lugar.

\section{REFERENCIAS BIBLIOGRÁFICAS}

AGURTO CALVO, Santiago

1974 Lima prehispánica. Lima: Municipalidad de Lima Metropolitana

BALDOCEDA, Ana

1993 Topónimos de Canta. Trabajo de Investigación. Lima: Instituto de Investigaciones Lingüísticas. 
BROMLEY, L. y BARBAGELATA

1980 Desarrollo urbano de Lima. Lima: Lumen.

CERRÓN PALOMINO, R., y otros

1983 Guía para estudios de toponimia. Lima: CILA.

$\mathrm{COBO}, \mathrm{B}$.

1956 Fundación de Lima. Madrid: Gráficos Orbe. (Obras completas. Vol. II.)

COLECCIÓN DOCUMENTAL DE LA INDEPENDENCIA DEL PERÚ 1976 Los ideólogos. Tomo I. Vol. III.

EGUIGUREN, L.A.

1945 Las calles de Lima. Lima: Municipalidad de Lima.

ESPINOZA, M.

1973 Topónimos quechuas del Perú. Lima: Comercial Santa Elena.

GUNTHER, J.

1983 Planos de Lima. Lima: Municipalidad de Lima.

KRZANOWSKI, A. y SZEMINSKI, J.

1974 La toponimia indígena en la cuenca del río Chicama (Perú) en Estudios latinoamericanos. Varsovia: Instituto de Historia de la Academia de Ciencias Polacas.

MENÉNDEZ PIDAL, R.

1968 Toponimia prerrománica hispánica. Madrid: Editorial Gredos.

RODRÍGUEZ, V.

1973-74 Razón de chacras y huertos de Lima. Lima: Estudios Americanos.

SANTILLÁN, T.

Cartografía y toponimia. Lima: Pontificia Universidad Católica del Perú. Tesis.

SOLÍS FONSECA, G.

1984 El topónimo Áncash y las limitaciones de una ciencia de la toponomia. Lima: Universidad Nacional Mayor de San Marcos, Centro de Investigación de Lingüística Aplicada. (Documento de Trabajo $\mathrm{N}^{\circ} 50$ ). 